\title{
Drug Induced Liver Injury (Dili) and Non Alcoholic Fatty Liver Disease (Nafld)
}

\author{
Goran Bokan, Nikola Malešević, Anna Licata, and Zoran Mavija
}

\begin{abstract}
This review article includes a review of the latest literature searched on PubMed in the field of hepatotoxicity caused by drugs that have a wide daily application. The concept of the review article consists of several parts dealing with the definition of drugs induced liver injury - DILI, diagnostic challenges related to it, and the clinical spectrum of liver disease, with an emphasis on the development of nonalcoholic fatty liver disease - NAFLD and review of drugs involved in formation of NAFLD.
\end{abstract}

\section{Index Terms - DILI, NAFLD, RUCAM, hepatotoxicit.}

\section{INTRODUCTION}

The term "drug-induced liver injury" (DILI) is a broad concept that also includes food-induced liver damage as well as dietary supplements and other nutrients [1]. The overall concept, including manifestation, early recognition, diagnosis and treatment of this is not well understood yet. In essence, it can be said it is based on the principle of exclusion. When all potential known etiologic agents as possible causes of liver damage are excluded, then a diagnosis of DILI can be made [2]. This is certainly a major challenge for every healthcare system worldwide, as it requires extensive diagnostic treatment of patients, which is correlated with the increase in financial allocations for the same purposes, and great expertise in clinicians who have already encountered similar cases, i.e. experience with DILI [3]. DILI is present in every country around the world, with different incidence and prevalence, which have not been precisely defined yet. As to why, is it still difficult to give a definite answer. It is assumed that some health systems are more developed and richer than others, have more clinical experience with DILI, and the number of people using the resources of one health system varies from country to country. Different treatments play an important role too, given that still some healthcare systems adhere to traditional treatment modalities [4], [5].

When analyzing the data of published studies in the last three decades, it can be concluded that the highest incidence is in Asian countries (about 90 per 100,000), while in European countries the incidence ranges from 2.4 in the UK, Italy 4.1, 13.9 in France to 19.4 in 100,000 in Iceland [6],

Published on August 29, 2020.

Goran Bokan, University Clinical Center of Republic of Srpska, Bośnia i Hercegowina.

(corresponding e-mail: bokan.goran ${ }^{\circledR}$ yahoo.com)

Nikola Malešević, University Clinical Center of Republic of Srpska, Bośnia i Hercegowina.

Anna Licata, University of Palermo Medical School, Italy.

Zoran Mavija, University Clinical Center of Republic of Srpska, Bośnia i Hercegowina.
[7]. The highest incidence in Asian countries is probably due to traditional medicine and the use of herbs and herbal supplements for therapeutic purposes. This type of treatment is not common in European countries but owing to the wide range of non-evidence-based medicines available in many online stores, this incidence is expected to increase in Europe as well [8], [9].

\section{Challenges In Diagnosing Of Dili}

A peculiar challenge in identifying and diagnosing DILI is the treatment of a known liver condition and the consequential therapy. Patients with a known liver disease may have abnormalities in the hepatogram, like an increase in liver enzymes, for two reasons: the first one is due to the undesirable effect of the drug; the second can be ascribed to the latency phase of a silent hepatic disease, without any clinical presentations [10]-[12].

The link between medication and an already-known liver disease is not well known, and great efforts are still being made to investigate it. So far, two types of drug-induced liver damage have been known and described, the idiosyncratic and intrinsic type [2]. The idiosyncratic type of damage is consequential to taking the drug at the usual therapeutic dose and an unexpected reaction occurs, which may be metabolic or immunological. This type of reaction is usually manifested by the type of delayed reaction. Some studies have proven that a delayed type of reaction by type of idiosyncrasy could occur after taking amoxicillin with clavulanic acid for therapeutic purposes. Such a reaction could occur after a few weeks, or another cases, like with the use of nitrofurantoin, after a few months. At the tissue level, this type of reaction can be evinced by the onset of inflammation, and clinical abnormalities in hepatospecific enzymes, their increase, fever, urticaria, indigestion or eosinophilia in differential blood counts [4], [6], [13]-[15]. Intrinsic type is a type of predictable reaction to a drug that is usually taken at a dose higher than the usual dose. An example of this type of reaction is the abnormal response to paracetamol in some patients [2].

At the tissue level, manifestations include necrosis or programmed cell death-apoptosis, while signs of inflammation are almost absent [13], [14]. Whether either of the two above-mentioned kinds of inflammation is present, both can lead to acute liver failure that requires immediate transplantation [16].

Diagnosis of DILI is a major challenge and, as mentioned above, it is based on the principle of exclusion. After taking a history of the present or previous diseases, as well as current therapy, after having obtained results of laboratory parameters, the current issues can then be analyzed. Laboratory parameters in DILI include the increase of the 
levels of liver enzymes, which can be higher by multiple times and it is also correlated with drug intake, early liver damage, possible drug interactions in polypharmacy and or drink/drug interactions, most commonly alcohol. Based on the increase in the value of the hepatospecific enzymes AST and ALT, the cholestatic enzymes GGT and ALP, and bilirubin, it can be concluded whether this is a hepatocellular, cholestatic or mixed type of damage [13], [14], [17]. If the ratio (R) between ALT and ALP is more than five times, then a hepatocellular type of damage can be taken into account; if it is less than two times, a cholestatic damage can be regarded [18]. There are numerous updates to the guidelines, the most recent of which indicates that DILI can be suspected when ALT is five times higher than its normal values and ALP is two times higher; moreover, it can be contemplated the increase in ALT three times higher its normal level, combined with the increase in bilirubin in more than double its normal value [19], [20]. After having examined laboratory diagnostics and differentiated the type of tissue damage in the liver, the exclusion of large and small hepatotropic viruses, HAV, HBV, HCV, CMV, EBV, as well as HSV, VZV should be performed through the determination of autoantibody titles such as AMA, ANA, pANCA, cANCA, ASMA, LKM, and immunoglobulin values [21]-[26]. Significant helps in diagnostics, such as ultrasound, fibro scan, computed tomography (CT), nuclear magnetic resonance imaging (NMR), liver biopsy and pathohistological verification of the disease must be considered [26], [27].

Thanks to RUCAM (Roussel Uclaf Causality Assessment Method), it is partly easier to reach a diagnosis of DILI. Data quantitatively evaluated at RUCAM are: latency period length, recurrent increase in hepatospecific enzymes, risk factors, individual co-medication, alternative causes, markers of large and small hepatotropic viruses, evaluation of cardiac hepatology, imaging diagnostics of liver and biliary tree, hepatic doppler diagnostics, data on previous hepatotoxicity and toxic substance exposure. The cumulative value of the score obtained is stratified in the range of -3 to +14 ; according to the value obtained, the probability that a drug has led to DILI is classified as highly probable, probable, possible, less probable or excluded [23], [28], [29].

\section{The CONCEPt Of NAFLD AND DiAgnosing Of Dili IN NAFLD PATIENTS}

The NAFLD (non-alcoholic fatty liver disease) phenotype can entail two different entities, namely NAFL (nonalcoholic fatty liver) and NASH (non-alcoholic steatohepatitis). While NAFL implies the presence of noninflammatory steatosis, NASH is defined as the presence of inflammatory steatosis and hepatocyte damage [30].

NAFLD is a manifestation of metabolic syndrome and is commonly associated with obesity, dyslipidemia and type 2 diabetes. NAFLD is the most common cause of chronic liver damage in the USA, affecting $1 / 3$ of the population [31], [32].

Hepatic steatosis (NAFL) is defined as the deposition of fat within hepatocytes. There are two types of steatosis: the microvesicular one is characterized by the accumulation of multiple individual fat droplets within the hepatocytes and centralization of the nucleus, while macrovesicular steatosis is characterized by the appearance of a large fat vesicle that pushes the nucleus towards the periphery of the hepatocyte. The diagnosis of DILI in patients with NAFL/NASH is made on the basis of the following criteria: biochemical and histological indicators of hepatic impairment, time frame from exposure to the onset of the first signs of hepatic impairment, data on improvement of hepatic function after discontinuation of therapy [33].

Among all the scoring systems, RUCAM is the most accurate in diagnosing of DILI in NAFLD patients [34], [35].

\section{The Clinical Spectrum Of Liver Disease And How NAFLD IS FORMED}

The clinical spectrum of liver disease comprises several clinical entities: steatosis, steatohepatitis, fibrosis, cirrhosis and hepatocellular carcinoma (HCC). Steatosis, or nonalcoholic fatty liver, is the most common liver disease with a prevalence of between 20 and $30 \%$ and has been increasing over the last decade. In some cases, the prevalence ranges from over $50 \%$ in obese or diabetic patients. In rare cases, drugs are the cause of DILI; some authors suggest that in less than $2 \%$ of cases [36]-[38]. The accumulation of fat droplets within hepatocytes is a foreign body to the immune system at the cellular level, thus inducing the chemotaxis of leukocytes and other cells and leading to an inflammatory reaction with consequential interleukin and mediator formation, then causing steatohepatitis. Steatosis and steatohepatits in a particular segment are conditions that can be halted before complete liver damage occurs [39], [40]. Long-chain free fatty acids (FFAs) enter the respiratory chain of the mitochondria due to the transport mechanism, reacting with coenzyme $A$, and the process of $\beta$-oxidation leads to the formation of acetyl-CoA. If $\beta$-oxidation inhibition occurs, the FFA concentration will increase, which inevitably leads to the synthesis of triglycerides (TGs) by the esterification process. Transport of triglycerides as VLDL may be blocked by some drugs, resulting in the formation of ROS. Certain drugs damage mtDNA. The progression of steatosis to steatohepatitis occurs due to disorders in the level of $\beta$-oxidation of fatty acids and increased production of ROS with consequent formation of mediators. Failure to stop exposure to the toxic knockout process inevitably leads to fibrosis and later cirrhosis [41]-[45]. A pharmaco-epidemiological prospective study group of Indiana authors suggests that individuals with CLD such as NAFLD are at increased risk for developing DILI in the United States, up to four times higher risk for patients with NAFLD for DILI than patients with hepatitis C [46].

In an Italian prospective study by Tarantino $\mathrm{G}$ et al., 74 patients had NAFLD. Six patients in this group had acute hepatitis associated with the following drug groups: antihypertensive, antiplatelets, antimicrobial, PPI, and NSAIDs. This group of authors also suggest that NAFLD is characterized by mitochondrial dysfunction, which has the same basis as DILI occurring in middle-aged usually obese people [47]. 


\section{DRugs InVOlVed In Formation Of NAFLD}

The drugs that cause NAFLD are divided according to the type of steatosis they cause, microvesicular or macrovesicular steatosis. The action of the drug may affect one of the biosynthetic processes, such as increased mitochondrial permeability, inhibition of fatty acid oxidation, oxidative phosphorylation, direct inhibition of the mitochondrial respiratory chain and depletion, or mtDNA damage. The precursors of drugs that lead to microvesicular steatosis are paracetamol/acetaminophen, NSAIDs (ibuprofen, naproxen, diclofenac, and aspirin), zidovudine/stavudine, and tetracyclines. Macrovascular steatosis is caused by methotrexate, tamoxifen, 5fluorouracil, and glucocorticoids. Amiodarone and valproate can cause both types of steatosis. The Table 1 presents the drugs that most commonly lead to NAFLD and the mechanism of their action [48]-[63].

TABLE 1: Drugs Causing Steatosis And Steatohepatitis

\begin{tabular}{|c|c|c|c|c|c|c|c|}
\hline DRUG & Type of steatosis & $\begin{array}{c}\text { MPTP } \\
\text { opening }\end{array}$ & $\begin{array}{l}\text { Direct inhibition of } \\
\text { mitochondria FAO }\end{array}$ & $\begin{array}{c}\text { OXPHOS } \\
\text { uncoupling }\end{array}$ & & $\begin{array}{l}\text { Direct inhibition } \\
\text { of the MRC }\end{array}$ & $\begin{array}{c}\text { mtDNA } \\
\text { depletion/damage }\end{array}$ \\
\hline Acetaminophen (APAP) & microvesicular & + & & & & + & + \\
\hline $\begin{array}{l}\text { NSAID (Ibuprofen and } \\
\text { naproxen) }\end{array}$ & microvesicular & & & & + & + & \\
\hline NSAID (diclofenac) & microvesicular & + & + & & + & & \\
\hline NSAID (aspirin) & microvesicular & + & + & & + & & \\
\hline Valproat & $\begin{array}{l}\text { microvesicular and } \\
\text { macrovesicular }\end{array}$ & + & + & & & & \\
\hline Zidovudine/Stavudine & microvesicular & & & & & & + \\
\hline Tetracycline & microvesicular & & + & & & & \\
\hline Amiodaron & $\begin{array}{l}\text { macrovesicular and } \\
\text { microvesicular }\end{array}$ & + & + & & + & + & \\
\hline Methotrexate & macrovesicular & & + & & & + & \\
\hline Tamoxifen & macrovesicular & & + & & + & + & + \\
\hline 5-fluorouracil & macrovesicular & & + & & & & \\
\hline Glucocorticoids & macrovesicular & & + & & & + & \\
\hline
\end{tabular}

Abbreviations: MPTP: mitochondrial permeability transition pores: FAO: fatty acid oxidation; OXPHOS: oxidative phosphorylation; MRC: mitochondrial respiratory chain, mtDNA: mitochondrial DNA.

Amiodarone is an antiarrhythmic drug considered to be a hepatic mitochondrial toxin that inhibits both enzyme complexes into electron transport by acting on $\beta$-oxidation. It is clinically presented with an increase in serum transaminases in $40-80 \%$ of cases. Histologically, it is characterized by steatohepatitis, balloon degeneration, and inflammatory PMN inflation, as well as micro vesicular seatosis [64], [65].

Aspirin leads to microvesicular steatosis by blocking the process of $\beta$-oxidation of fatty acids and increasing mitochondrial permeability. Aspirin used in young children for viral infection therapy can lead to Reye syndrome, manifested by $\beta$-oxidation of fatty acids and increased ureagenesis, ketogenesis, and severe hypoglycemia due to the inability to convert lactate into glucose. Diffuse microvesicular steatosis was seen in advanced fatal disease [66], [67]

Tetracyclines were administered intravenously until 1991 when they were found to lead to fulminant hepatitis, which often proved to be fatal. The principle of action was based on inhibition of VLDL secretion and inhibition of $\beta$ oxidation [68].

NSAIDs are the leading causes of hepatotoxicity and can lead to hepatocellular or holeostatic type of damage that ends in acute liver failure. Only some have been shown to cause steatosis, most commonly proxene and ibuprofen [69], [70]. Methotrexate is a folate antagonist. It is used as a chemotherapeutic and immunosuppressant in the treatment of IBD, psoriasis and RA. Its hepatotoxic effect is cumulative and its range of toxicity ranges from steatosis/steathepatitis, focular necrosis to even cirrhosis. Methotrexate also inhibits mitochondrial electron transport [71]-[73].

Glucocorticosteroids are immunosuppressive used in the treatment of autoimmune diseases. Long-term administration causes weight gain, dyslipidemia and glucose intolerance with worsening metabolic syndrome leading to steatosis and steatohepatitis. They inhibit $\beta$-oxidation of fatty acids, reduce triglyceride secretion and induce fat peroxidation [74].

\section{CONCLUSION}

The findings to date, and the retrospective and prospective studies conducted, raise the suspicion of an increase in the incidence of DILI in patients with NAFLD, especially middle-aged people with metabolic syndrome. There are uncertainties regarding the setting of precise DILI diagnostic criteria due to the inability to understand the causality of the current presentation of hepatic lesions. Because of this reason, DILI remains a diagnosis that is deducted by the principle of exclusion.

\section{ACKNOWLEDGMENT}

We are grateful to the director of the University Clinical Center of Banja Luka, Prof. Dr. Vlado Đajić, for all the support. 


\section{REFERENCES}

[1] Bjornsson ES. Drug-induced liver injury: an overview over the most critical compound. ArchToxicol 2015; 89: 327-334.

[2] Zimmerman HJ. Hepatotoxicity. The adverse effects of drugs and other chemicals on the liver. 2nd ed. Philadelphia: Lippincott Williams \& Wilkins; 1999.

[3] Licata A, Minissale MG, Caruso V, Craxi A. A focus on epidemioogy of drug-induced liver injury: analysis of a prospective cohort: Eur Rey Med Pharmacol Sci. 2017; 21(1 Suppl): 112-121.

[4] Björnsson E, Olsson R. Suspected drug induced liver fatalities reported to the WHO database. Dig Liv Dis 2006;38:33-8.

[5] Chen M, Suzuki A, Borlak J, Andrade RJ, Lucena MI. Drug-induced liver injury: Interactions between drug properties and host factors. J Hepatology 2015; 63:503-14.

[6] Kim SH, Naisbitt DJ. Update on Advances in Research of Idiosyncratic Drug Induced Liver Injury. Allergy Asthma Immunol Res 2016;8:3-11.

[7] Björnsson E. Drug-induced liver injury in clinical practice. Aliment Pharmacol Ther 2010; 32: 3-13.

[8] Zaffani S, Cuzzolin L, Benoni G: Herbal products: behaviours and beliefs among Italian women. Pharmacoepidemiol Drug Saf 2006; 15 : 354-359.

[9] Gordon DW, Rosenthal G, Hart J, Sirota R, Baker AL. Chaparral ingestion. The broadening spectrum of liver injury caused by herbal medications. JAMA 1995; 273: 489-490.

[10] Watkins, P.B., Seligman, P.J., Pears, J.S. et al. Using controlled clinical trials to learn more about acute drug-induced liver injury. Hepatology. 2008; 48: 1680-1689.

[11] Chalasani, N. and Bjornsson, E. Risk factors for idiosyncratic druginduced liver injury. Gastroenterology. 2010; 138: 2246-225.

[12] Russo, M.W. and Watkins, P.B. Are patients with elevated liver tests at increased risk of drug-induced liver injury?. Gastroenterology. 2004; 126: 1477-1480.

[13] Abboud G., Kaplowitz N. Drug-Induced Liver Injury. Drug Saf 2007; 30: 277-94.

[14] Suzuki A, Andrade RJ, Bjornsson E, Lucena MI, William ML, Yuen NA et al. Drugs Associated with Hepatotoxicity and their Reporting Frequency of Liver Adverse Evenets in VigiBase Drug Sad 2010;33:503-22.

[15] Adams DH, Ju C, Ramaiah SK, Uetrecht J, Jaeschke H. Mechanisms of immune-mediated liver injury. Toxicol Sci 2010; 115:307-21.

[16] Fontana RJ. Acute liver failure including acetaminophen overdose. Med Clin North Am. 2008;92:761-94.

[17] Lewis JH, Ahmed M, Shobassy A, Palese C. Drug-induced liver disease. Curr Opin Gastroenterol 2006; 22:223-33.

[18] Chalasani P, Hayashi P, Bonkovsky H, Navarro V, Lee W. ACG Clinical Guideline: the diagnosis andmanagement of Idiosyncratic Drug-Induced Liver Injury. Am J Gastroenterol 2014; 109: 950-966.

[19] Food and Drug Administration. Drug-induced livery injury: premarketing clinical evaluation. In: Guidance for industry. 2009.

[20] Jalan, R., Gines, P., Olson, J.C. et al. Acute-on chronic liver failure. J Hepatol. 2012; 57: 1336-1348.

[21] Navarro VJ, Senior JR. Drug related hepatotoxicity. N Engl J Med 2006; 354: 731-739.

[22] Reuben A, Koch DG, Lee WM. Drug induced acute liver failure: results of a US multicenter, prospective study. Hepatology 2010; 52 : 2065-2076.

[23] Danan G. The Roussel Uclaf Causality Assessment Method (RUCAM) score is based upon a modification of the original scoring system of the Council for International Organizations of Medical Sciences (CIOMS) and supported by Roussel Uclaf Pharmaceuticals. Consensus Meetings on: causality assessment of drug-induced liver injury. J Hepatol 1988; 7: 132-136.

[24] Danan G, Benichou C. Causality assessment of adverse reaction to drugs--A novel method based on the conclusions of international consensus meeting: application to drug-induced liver injuries. J Clin Epidemiol 1993; 46: 1323-1330.

[25] Benichou, Danan G, Flahault A. Causality assessment of adverse reactions to drugs. An original model for validation of drug causality assessment methods: case reports with positive rechallenge. J Clin Epidemiol 1993; 46: 1331-1336.

[26] Maria VA, Victorino RM. Development and validation of a clinical scale for the diagnosis of drug induced hepatitis. Hepatology 1997; 26: 664-669.

[27] Chalasani N, Fontana RJ, Bonkovsky Hl. Causes, clinical features, and outcomes from a prospective study of drug induced liver injury in the United States. Gastroenterology 2008; 135: 1924-1934.

[28] Benichou C, Danan G, Flahault A. Causality assessment of adverse reactions to drugs--II. An original model for validation of drug causality assessment methods: case reports with positive rechallenge. J Clin Epidemiol 1993; 46: 1331-1336.

[29] Danan G, Teschke R. RUCAM in drug and herb induced liver injury: the update. Int J Mol Sci. 2016;17(1). doi: 10.3390/ijms17010014. Special issue: Drug, herb, and dietary supplement hepatotoxicity.

[30] Chalasani N, Younossi Z, Lavine JE, et al. The diagnosis and management of non-alcoholic fatty liver disease: practice guideline by the American Association for the Study of Liver Diseases, American College of Gastroenterology, and the American Gastroenterological Association. Hepatology. 2012;55:2005-23.

[31] Dam-Larsen S, Franzmann M, Andersen IB, et al. Long term prognosis of fatty liver: risk of chronic liver disease and death. Gut. 2004;53:750-5.

[32] Matteoni CA, Younossi ZM, Gramlich T, et al. Nonalcoholic fatty liver disease: a spectrum of clinical and pathological severity. Gastroenterology. 1999;116:1413-9.

[33] Marchesini G, Bugianesi E, Forlani G, et al. Nonalcoholic fatty liver, steatohepatitis, and the metabolic syndrome. Hepatology. 2003;37:917-23.

[34] Benichou C, Danan G, Flahault A. Causality assessment of adverse reactions to drugs-II. An original model for validation of drug causality assessment methods: case reports with positive rechallenge. J Clin Epidemiol. 1993;46:1331-6.

[35] 9. Danan G, Benichou C. Causality assessment of adverse reactions to drugs-I. A novel method based on the conclusions of international consensus meetings: application to drug-induced liver injuries. J Clin Epidemiol. 1993;46:1323-30.

[36] M. Lazo, R. Hernaez, M. S. Eberhardt et al., "Prevalence of nonalcoholic fatty liver disease in the United States: the third national health and nutrition examination survey, 1988-1994," American Journal of Epidemiology, vol. 178, no. 1, pp. 38-45, 2013.

[37] J. D. Browning, L. S. Szczepaniak, R. Dobbins et al., "Prevalence of hepatic steatosis in an urban population in the United States: impact of ethnicity," Hepatology, vol. 40, no. 6, pp. 1387-1395, 2004.

[38] A. Grieco, A. Forgione, L. Miele et al., "Fatty liver and drugs," European Review for Medical and Pharmacological Sciences, vol. 9, no. 5, pp. 261-263, 2005 .

[39] . W. Guglielmi, D. Boggio-Bertinet, A. Federico et al., "Total parenteral nutrition-related gastroenterological complications," Digestive and Liver Disease, vol. 38, no. 9, pp. 623 $642,2006$.

[40] Musso G., Gambino R., Cassader M.Non-alcoholic fatty liver disease from pathogenesis to management: an update Obes Rev, 11 (2010), pp. $430-445$

[41] Stravitz RT, Sanyal AJ. Drug-induced steatohepatitis. Clin Liver Dis. 2003; 7:435-51.

[42] Pessayre D, Fromenty B, Berson A, et al. Central role of mitochondria in drug-induced liver injury. Drug Metab Rev. 2012;44:34-87.

[43] Fromenty B, Pessayre D. Inhibition of mitochondrial beta-oxidation as a mechanism of hepatotoxicity. Pharmacol Ther. 1995;67:101-54.

[44] Koek GH, Liedorp PR, Bast A. The role of oxidative stress in nonalcoholic steatohepatitis. Clin Chim Acta. 2011;412:1297-305.

[45] Kimura S, Kobayashi T, Tanaka Y, et al. Liver histopathology in clinical Reye syndrome. Brain Dev. 1991;13:95-100.

[46] Lammert C, Imler T, Teal E et al. Patients with chronic liver disease suggestive of nonalcoholic fatty liver disease may be at higher risk for drug-induced liver injury. Clin Gastroenterol Hepatol. 2018; S1542 3565(18)31389-2

[47] Tarantino G, Conca P, Basile V et al. A prospective studz of acute drug-induced liver injury in patients suffering from non-alcoholic liver disease. Hep Resarch 2007; 37: 410-415.

[48] Patel V, Sanyal AJ,. Drug-induced steatohepatitis. Clin Liver Dis 2013 Nov; 17(4): 533-546

[49] Curguz A, Nežić L, Mandić M. Drug Induced Liver Injury: Pathogenesis, Clinical Features and Monitoring Scr Med 2016:47:140-147.

[50] Satapathy SK, kuwajima V, Nadelson J et al. Drug-induced fatty liver disease: An overview of pathogenesis and management. Annals of Hepatology2015; 14(6):789-806.

[51] Chen C, Krausz KW, Shah YM, Idle JR, Gonzalez FJ. Serum metabolomics reveals irreversible inhibition of fatty acidbetaoxidation through the suppression of PPARalpha ac-tivation as a contributing mechanism of acetaminophen-induced hepatotoxicity Chem Res Toxicol 2009; 22:699-707.

[52] Burcham PC, Harman AW. Acetaminophen toxicity resultsin sitespecific mitochondrial damage in isolated mousehepatocytes. J Biol Chem 1991; 266: 5049-54

[53] Freneaux E, romenty B, Berson A, Labbe G, Degott C,Letteron P, Larrey D, et al. Stereoselective and nonster-eoselective effects of 
ibuprofen enantiomers on mito-chondrial beta-oxidation of fatty acids. J Pharmacol ExpTher 1990; 255: 529-35.

[54] Moreno-Sanchez R, Bravo C, Vasquez C, Ayala G, SilveiraLH, Martinez-Lavin M. Inhibition and uncoupling of oxida-tive phosphorylation by nonsteroidal anti-inflammatorydrugs: study in mitochondria, submitochondrial parti-cles, cells, and whole heart. Biochem Pharmacol 1999;57: 743-52.

[55] Boelsterli UA. Diclofenac-induced liver injury: a paradigmof idiosyncratic drug toxicity. Toxicol Appl Pharmacol2003; 192: 30722.

[56] Trost LC, Lemasters JJ. Role of the mitochondrial per-meability transition in salicylate toxicity to culturedrat hepatocytes: implications for the pathogenesis ofReye's syndrome. Toxicol Appl Pharmacol 1997; 147:431-41.

[57] Deschamps D, Fisch C, Fromenty B, Berson A, Degott C,Pessayre D. Inhibition by salicylic acid of the activationand thus oxidation of long chain fatty acids. Possible rolein the development of Reye's syndrome. J Pharmacol ExpTher 1991; 259: 894-904.

[58] Spaniol M, Bracher R, Ha HR, Follath F, Krähenbühl S. Tox-icity of amiodarone and amiodarone analogues on isolat-ed rat liver mitochondria. J Hepatol 2001; 35: 628-36.

[59] Kakuda TN. Pharmacology of nucleoside and nucleotidereverse transcriptase inhibitor-induced mitochondrialtoxicity. Clin Ther 2000; 22: 685-708.

[60] Silva MF, Aires CC, Luis PB, Ruiter JP, IJlst L, Duran M,Wanders RJ, et al. Valproic acid metabolism and its ef-fects on mitochondrial fatty acid oxidation: a review. JInherit Metab Dis 2008; 31: 205-16.

[61] Lemasters JJ, Nieminen AL, Qian T, Trost LC, Elmore SP,Nishimura $\mathrm{Y}$, Crowe RA, et al. The mitochondrial permea-bility transition in cell death: a common mechanism innecrosis, apoptosis and autophagy. Biochim Biophys Acta1998; 1366: 177-96

[62] Larosche I, Letteron P, Fromenty B, Vadrot N, Abbey-Toby A, Feldmann G, Pessayre D, et al. Tamoxifen inhibitstopoisomerases, depletes mitochondrial DNA, and triggerssteatosis in mouse liver. J Pharmacol Exp Ther 2007; 321:526-35.

[63] Labbe G, Pessayre D, Fromenty B. Drug-induced liver inju-ry through mitochondrial dysfunction: mechanisms and de-tection during preclinical safety studies. Fundam ClinPharmacol 2008; 22 335-53.

[64] Grieco A, Forgione A, Miele L, Vero V, Greco AV, Gasbar-rini A, Gasbarrini G. Fatty liver and drugs. Eur Rev MedPharmacol Sci 2005; 9: 261-3.

[65] Sopher SM, Camm AJ. Adverse effects of amiodarone atlow dose: plus ca change. J Am Coll Cardiol 1997; 30:799-801.

[66] Kimura S, Kobayashi T, Tanaka Y, et al. Liver histopathology in clinical Reye syndrome. Brain Dev. 1991;13:95-100.

[67] Oh KW, Qian T, Brenner DA, et al. Salicylate enhances necrosis and apoptosis mediated by the mitochondrial permeability transition. Toxicol Sci. 2003;73:44-52.

[68] Letteron P, Sutton A, Mansouri A, et al. Inhibition of microsomal triglyceride transfer protein: another mechanism for drug-induced steatosis in mice. Hepatology. 2003;38:133-40.

[69] Freneaux E, Fromenty B, Berson A, et al. Stereoselective and nonstereoselective effects of ibuprofen enantiomers on mitochondrial beta-oxidation of fatty acids. J Pharmacol Exp Ther. 1990;255:52935 .

[70] 40. Victorino RM, Silveira JC, Baptista A, et al. Jaundice associated with naproxen. Postgrad Med J. 1980;56:368-70.

[71] Berends MA, van Oijen MG, Snoek J, et al. Reliability of the Roenigk classification of liver damage after methotrexate treatment for psoriasis: a clinicopathologic study of 160 liver biopsy specimens. Arch Dermatol. 2007; 143:1515-9.

[72] 69. Hytiroglou P, Tobias H, Saxena R, et al. The canals of Hering might represent a target of methotrexate hepatic toxicity. Am J Clin Pathol. 2004;121:324-9. 70.

[73] Yamamoto N, Oliveira MB, de Campello AP, et al. Methotrexate: studies on the cellular metabolism. I. Effect on mitochondrial oxygen uptake and oxidative phosphorylation. Cell Biochem Funct. 1988;6:61-6.

[74] Letteron P, Fromenty B, Terris B, et al. Acute and chronic hepatic steatosis lead to in vivo lipid peroxidation in mice. $\mathrm{J}$ Hepatol. 1996;24:200-8. 